\title{
The influence of urban park characteristics on bird diversity in Nanjing, China
}

\author{
Xueru Yang, Xinwei Tan, Chuanwu Chen and Yanping Wang ${ }^{*}$ (i)
}

\begin{abstract}
Background: Habitat loss, fragmentation and decrease of habitat quality caused by urbanization have led to a dramatic decline in biodiversity worldwide. For highly urbanized areas, parks have become "islands" or habitat fragments for wildlife. As an important indicator group of urban ecosystem health, the response of birds to urbanization has attracted the global attention of ecologists. Understanding the key factors affecting bird diversity in urbanized environment is crucial to the protection of biodiversity in urban ecosystems.

Methods: We used the line-transect method to survey birds in 37 urban parks in Nanjing, China. We also measured a number of park characteristics (area, isolation, shape index, environmental noise, distance to city center, and habitat diversity) that are commonly assumed to influence bird diversity. We then used the information-theoretic multi-model inference approach to determine which park characteristics had significant impacts on bird species richness.

Results: We found that park area, habitat diversity and the distance to city center were the best positive predictors of bird species richness in Nanjing urban parks. By contrast, park isolation, park shape and environmental noise had little or no influence on bird diversity.

Conclusions: Our study highlights the importance of park area, habitat diversity and the distance to city center in determining bird diversity in Nanjing city parks. Therefore, from a conservation viewpoint, we recommend that large parks with complex and diverse habitats far away from the city center should be retained or constructed to increase bird diversity in urban design and planning.
\end{abstract}

Keywords: Biodiversity conservation, Bird diversity, Habitat diversity, Park area, Species richness, Urbanization, Urban parks

\section{Background}

The loss of biodiversity caused by urbanization is a serious problem that has aroused global concern (Grimm et al. 2008). With the development of urbanization, more and more natural land has been replaced by tall buildings and hardened roads (Ferenc et al. 2014). In this context, parks in urban areas often act as "islands" or habitat fragments for wildlife (Fernández-Juricic and Jokimäki 2001). Wildlife habitat management in parks is an effective way to protect biodiversity in urban ecosystems (Hagen et al.

*Correspondence: wangyp214@gmail.com

Jiangsu Key Laboratory for Biodiversity and Biotechnology, College of Life

Sciences, Nanjing Normal University, Nanjing 210023, China
2017). As an important part of biodiversity, birds are an important indicator group of urban ecosystem health (Lepczyk and Warren 2012). The impacts of urbanization on bird diversity and composition has become a hot topic in urban ecology (Evans et al. 2009; Aronson et al. 2014; Chen and Wang 2017).

Theoretical and empirical evidence suggests that bird diversity in urban areas is primarily determined by several key variables, including fragment area, isolation, shape, habitat diversity and human disturbance (MacArthur and Wilson 1967; Fernández-Juricic and Jokimäki 2001; Murgui 2007). First, according to the theory of island biogeography and species-area relationships, park area is often the most important determinates of 
bird diversity (MacArthur and Wilson 1967; Oliver et al. 2011; Schütz and Schulze 2015). Park area may influence species richness simply by the passive sampling effect, directly by its effects on immigrate and extinction rates (area per se), or indirectly through its positive correlation with habitat diversity (Ricklefs and Lovette 1999). Second, the isolation of urban parks often has negative influences on bird diversity because the inhospitable urban matrix will hinder the dispersal of bird species (MacArthur and Wilson 1967; Fernández-Juricic and Jokimäki 2001). Third, the shape of fragments may affect bird diversity by varying the edge-affected habitats (MartinezMorales 2005; Ewers and Didham 2007). Typically, the complex shaped fragment has a higher perimeter area ratio, which increases the fragment area affected by the strong edge effect (Laurance and Yensen 1991). Moreover, urbanization may lead to changes in habitat diversity among fragments, which in turn affects species richness (Jasmani et al. 2016). In addition, the distance to city center, a measure of the degree of urbanization, also positively affects bird diversity (Chen et al. 2000). Finally, human interference and environmental noise often have negative impacts on bird diversity in urban ecosystems (Nemeth and Brumm 2010; Gagné et al. 2016).

There are already some studies on bird diversity in Chinese city parks, although most of studies were published in Chinese (see Chen and Wang 2017 for reviews). For example, Liu et al. (2019) found that bird diversity in Chinese urban parks was more associated with natural factors than anthropogenic factors. Morelli et al. (2017) showed that land use composition and vegetation structure were the best predictors of taxonomic diversity, functional diversity and evolutionary uniqueness in bird communities of Beijing's urban parks. However, the influencing factors of bird diversity in Chinese city parks is highly variable in different cities (Zhou et al. 2012; Morelli et al. 2017; Liu et al. 2019), so we need to conduct local studies to develop appropriate conservation plans.

As the political, economic and cultural center of Jiangsu province, Nanjing is one of the most urbanized cities in the Yangtze River Delta region, China. The urbanization rate of Nanjing has reached $82 \%$ by 2016 , ranking among the top ten cities in China. Recent research has shown that great changes have taken place in human population and land use in Nanjing from 2000 to 2016 (Ding and Shi 2017). Specifically, the human population has increased from 6.238 million in 2000 to 8.236 million in 2016, with an increase rate of $32 \%$. The growth rate of urban construction land is as high as $54 \%$, and mountainous and primary forests has been transformed into urban residential area, grassland and other land use types, resulting in obvious changes in landscape pattern and high degree of fragmentation (Ding and Shi 2017). Such rapid urbanization of Nanjing may have serious impacts on bird diversity. Therefore, it is important to investigate the key factors affecting bird diversity so as to maintain and enhance bird diversity in this highly urbanized city.

In this study, we surveyed bird species richness and measured a number of park characteristics (area, isolation, shape index, environmental noise, distance to city center, and habitat diversity) in 37 urban parks of Nanjing, China. The objectives of this study were: (1) to evaluate the effects of park characteristics on bird species richness in our study system; and (2) to provide suggestions for the management and planning of urban parks that will improve bird diversity. Based on the theory of island biogeography and previous studies, we hypothesized that park area, habitat diversity and the distance to city center would positively affect bird species richness, while park isolation, park shape and environmental noise would negatively influence bird species richness.

\section{Methods \\ Study area}

Nanjing $\left(31^{\circ} 14^{\prime}-32^{\circ} 37^{\prime} \mathrm{N}, 118^{\circ} 22^{\prime}-119^{\circ} 14^{\prime} \mathrm{E}\right)$ is located in the southwest of Jiangsu Province and the middle and lower reaches of the Yangtze River, with a total area of $6597 \mathrm{~km}^{2}$. The terrain in the region is relatively flat and composed mainly by low mountains, hills and plains (Tong 2007). Nanjing belongs to the subtropical monsoon climate, with four distinct seasons. The annual average temperature is about $15.7{ }^{\circ} \mathrm{C}$, ranging from $-16.7^{\circ} \mathrm{C}$ in winter to $43^{\circ} \mathrm{C}$ in summer. The average annual precipitation is about $1106 \mathrm{~mm}$. The major vegetation in the region is evergreen and deciduous broadleaved forest (Cui 2015).

Nanjing is one of the four garden cities in China with an extensive network of parks. We chose a total of 37 city parks in the highly urbanized areas of Nanjing (Fig. 1) (Tan et al. 2020). Prior to the formal surveys, potential parks were determined by using the satellite map and field inspection. The majority of the parks were surrounded by the urban matrix that is inhospitable to birds, including the buildings or paved roads. All the parks were selected to represent a gradient of landscape variables (area, isolation, environmental noise and habitat types) (Table 1). For instance, the size of these parks ranged from 2 to 514 ha, and habitat diversity varied from 2 to 12 types (Table 1 ).

\section{Bird surveys}

From April 2019 to January 2020, we used the line-transect method (Bibby et al. 2000) to conduct a monthly survey of birds in the 37 study parks. During the survey, the observers used the CELESTRON $10 \times 42$ binoculars to watch birds and walked along each transect at a constant 


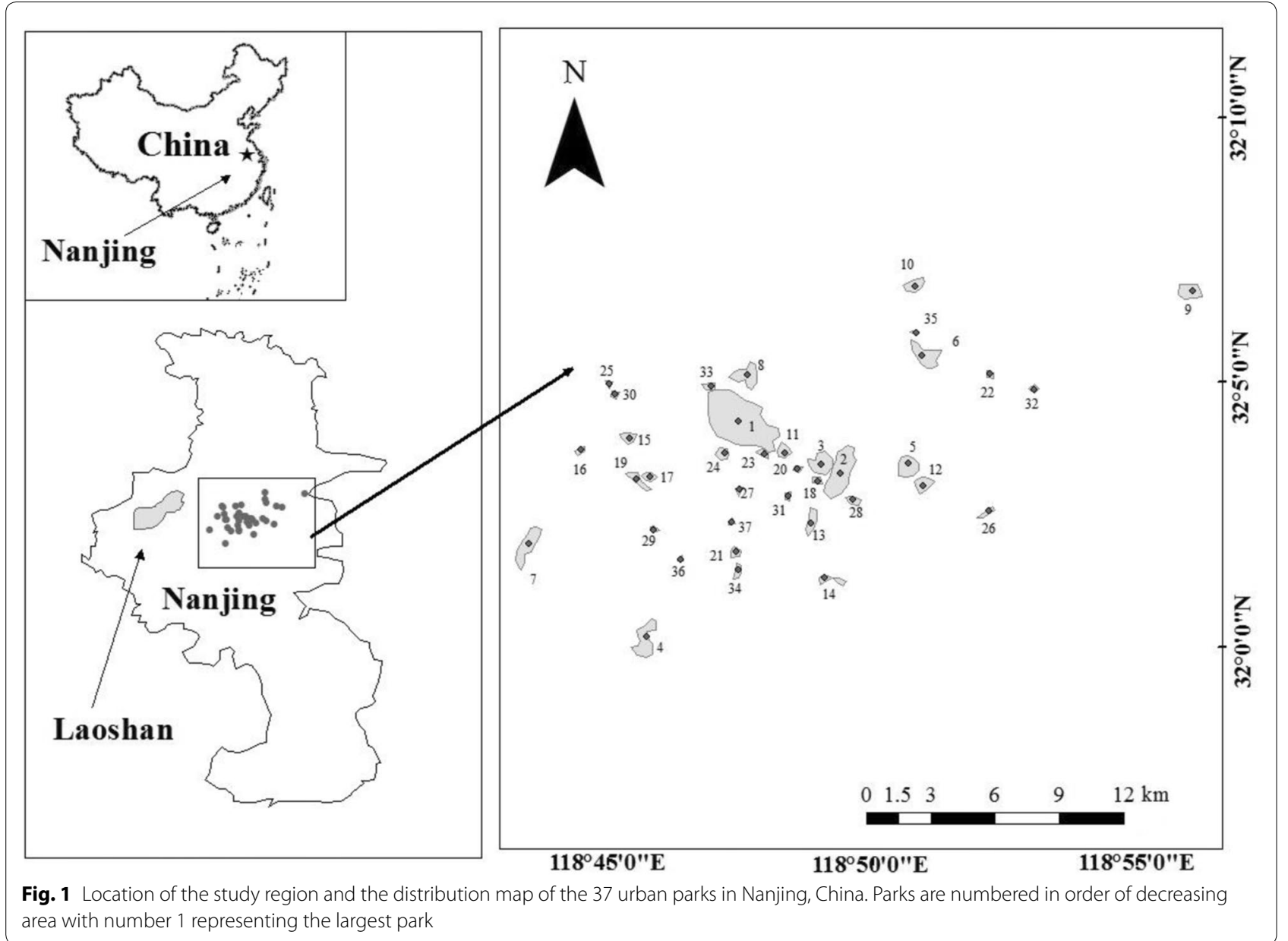

speed of $2.0 \mathrm{~km} / \mathrm{h}$. According to the area and shape of the park, each transect was determined that could run through the whole park to make a thorough search for all species (Fernández-Juricic 2000). We recorded the species richness and abundance of birds seen or heard within $50 \mathrm{~m}$ of the transects, except for those high-flying species (Wang et al. 2010). The survey time spent in each park ranged from 5 min to $2 \mathrm{~h}$. Considering the inactivity of birds in the mid-day period, surveys were conducted from dawn to 11:00 am and from 3:00 pm to sunset (Wang et al. 2010). We usually surveyed birds on sunny and windless days. The identification and classification of birds were based on A Field Guide to the Birds of China (Mackinnon and Phillipps 2000) and A Checklist on the Classification and Distribution of the Birds of China (Zheng 2017).

\section{Habitat variable surveys}

For each park, we selected six environmental variables to explore their impacts on bird diversity: (1) park area, (2) park isolation, (3) park shape index, (4) environmental noise, (5) distance to city center, and (6) habitat diversity. We used Google Earth 7.3.3 to obtain the area and perimeter of the 37 urban parks. The shape index (SI) indicates the relative shape complexity of parks, which is calculated with the formula: $\mathrm{SI}=P /\left[2 \times(\pi \times A)^{0.5}\right]$ (Ewers and Didham 2007), where $P$ is park perimeter and $A$ is park area. The shape of a park is circular when SI is 1 . With the increase of the shape index, the shape of the park becomes irregular and complex (Ewers and Didham 2007). Isolation 1 is defined as the distance from the park to the nearest larger park, and isolation 2 is the distance from the park to the unfragmented Laoshan National Forest Park (Table 1), both of which reflect the potential source of species for the smaller park (Fernández-Juricic 2000; Wang et al. 2013). Laoshan National Forest Park was considered to be a potential source of bird species in Nanjing parks due to its large size and low level of human exploitation. Environmental noise is an important index that reflects the degree of human interference (Wang et al. 2013). During the survey, we selected 3 to 5 sampling locations based on park area to measure the noise 
Table 1 Characteristics of the $\mathbf{3 7}$ study parks in Nanjing, China

\begin{tabular}{|c|c|c|c|c|c|c|c|c|c|c|}
\hline Park code & Park area (ha) & Distance (m) & Isolation1 (m) & Isolation2 (m) & $\begin{array}{l}\text { Number } \\
\text { of habitats } \\
(n)\end{array}$ & $\begin{array}{l}\text { Noise }(\mathrm{dB}) \\
(\text { mean } \pm \text { SD) }\end{array}$ & Shape index & $S_{\text {obs }}(n)$ & $S_{\exp }(n)$ & $S_{\text {com }}$ \\
\hline 1 & 514.68 & 2763.34 & 14307.45 & 14307.45 & 11 & $56.3 \pm 6.7$ & 1.15 & 41 & 44 & 0.93 \\
\hline 2 & 160.49 & 4510.33 & 2324.98 & 19078.69 & 11 & $57.6 \pm 1.7$ & 1.42 & 44 & 49 & 0.90 \\
\hline 3 & 100.64 & 3993.52 & 1122.29 & 17869.11 & 11 & $56.1 \pm 3.1$ & 1.17 & 36 & 45 & 0.80 \\
\hline 4 & 98.54 & 5167.56 & 7922.71 & 17352.86 & 4 & $59.0 \pm 4.3$ & 1.82 & 20 & 21 & 0.95 \\
\hline 5 & 63.66 & 7572.81 & 346.25 & 21753.38 & 8 & $60.8 \pm 3.5$ & 1.17 & 32 & 35 & 0.91 \\
\hline 6 & 62.39 & 10637.12 & 3977.97 & 22046.94 & 12 & $56.6 \pm 4.4$ & 1.52 & 45 & 60 & 0.75 \\
\hline 7 & 61.38 & 6776.72 & 8215.56 & 9966.08 & 10 & $53.9 \pm 2.0$ & 1.60 & 38 & 42 & 0.90 \\
\hline 8 & 52.51 & 5474.82 & 522.35 & 14387.74 & 7 & $58.5 \pm 6.0$ & 1.78 & 21 & 36 & 0.58 \\
\hline 9 & 45.33 & 20869.16 & 3229.51 & 32597.62 & 7 & $56.1 \pm 3.5$ & 1.13 & 34 & 46 & 0.74 \\
\hline 10 & 33.55 & 12558.95 & 2252.73 & 21774.77 & 6 & $56.6 \pm 1.5$ & 1.13 & 26 & 26 & 1.00 \\
\hline 11 & 33.33 & 3420.71 & 69.42 & 16962.47 & 9 & $59.5 \pm 1.7$ & 1.06 & 32 & 39 & 0.82 \\
\hline 12 & 29.85 & 8047.15 & 335.05 & 22393.22 & 5 & $55.8 \pm 4.6$ & 1.24 & 28 & 30 & 0.93 \\
\hline 13 & 29.60 & 3919.39 & 665.75 & 18868.94 & 6 & $58.6 \pm 7.1$ & 1.95 & 27 & 31 & 0.87 \\
\hline 14 & 29.25 & 5488.70 & 1784.88 & 20425.40 & 10 & $59.4 \pm 1.2$ & 1.56 & 46 & 53 & 0.87 \\
\hline 15 & 21.04 & 3993.33 & 2946.17 & 10856.04 & 11 & $57.0 \pm 5.2$ & 1.13 & 29 & 35 & 0.83 \\
\hline 16 & 18.67 & 5272.27 & 1409.22 & 9343.43 & 5 & $52.1 \pm 3.8$ & 1.06 & 23 & 28 & 0.82 \\
\hline 17 & 18.33 & 2273.25 & 1545.59 & 12079.61 & 4 & $58.2 \pm 1.8$ & 1.20 & 17 & 17 & 1.00 \\
\hline 18 & 17.78 & 4164.21 & 19.50 & 18536.24 & 5 & $58.3 \pm 4.4$ & 1.07 & 25 & 27 & 0.93 \\
\hline 19 & 16.94 & 2805.10 & 74.49 & 11619.00 & 4 & $57.7 \pm 1.5$ & 1.37 & 25 & 27 & 0.93 \\
\hline 20 & 16.58 & 3696.73 & 285.73 & 17773.20 & 6 & $55.0 \pm 4.3$ & 1.37 & 29 & 33 & 0.88 \\
\hline 21 & 15.93 & 2276.21 & 2730.40 & 16778.58 & 5 & $56.5 \pm 6.0$ & 1.08 & 19 & 25 & 0.76 \\
\hline 22 & 14.82 & 12331.95 & 1668.50 & 24553.20 & 8 & $60.1 \pm 3.1$ & 1.38 & 27 & 32 & 0.84 \\
\hline 23 & 12.95 & 2943.27 & 43.45 & 15664.05 & 7 & $56.2 \pm 5.3$ & 1.76 & 27 & 33 & 0.82 \\
\hline 24 & 11.95 & 2155.60 & 304.18 & 14586.09 & 4 & $56.4 \pm 6.1$ & 1.22 & 23 & 26 & 0.88 \\
\hline 25 & 9.56 & 6431.38 & 2105.76 & 9871.16 & 5 & $53.1 \pm 1.7$ & 1.36 & 16 & 22 & 0.73 \\
\hline 26 & 9.35 & 10449.00 & 2359.27 & 25113.73 & 6 & $60.7 \pm 3.0$ & 1.62 & 23 & 26 & 0.88 \\
\hline 27 & 9.30 & 1032.89 & 1398.77 & 15782.83 & 5 & $54.4 \pm 2.8$ & 1.14 & 15 & 15 & 1.00 \\
\hline 28 & 9.18 & 5438.14 & 422.54 & 20151.01 & 10 & $52.0 \pm 3.1$ & 1.24 & 23 & 26 & 0.88 \\
\hline 29 & 9.10 & 2297.65 & 2074.84 & 13624.55 & 5 & $60.3 \pm 5.9$ & 1.21 & 23 & 23 & 1.00 \\
\hline 30 & 8.50 & 5947.61 & 94.31 & 10171.32 & 4 & $59.4 \pm 3.5$ & 1.38 & 20 & 21 & 0.95 \\
\hline 31 & 5.28 & 2986.01 & 858.19 & 17664.24 & 5 & $61.0 \pm 3.0$ & 1.30 & 16 & 17 & 0.94 \\
\hline 32 & 4.76 & 13643.02 & 1393.01 & 26500.65 & 5 & $56.8 \pm 1.9$ & 1.20 & 24 & 30 & 0.80 \\
\hline 33 & 4.60 & 5384.31 & 253.50 & 13731.47 & 5 & $59.9 \pm 3.9$ & 1.48 & 18 & 19 & 0.95 \\
\hline 34 & 4.40 & 2982.04 & 192.68 & 17255.82 & 5 & $63.7 \pm 4.0$ & 2.15 & 21 & 21 & 1.00 \\
\hline 35 & 3.54 & 11264.40 & 185.67 & 21861.83 & 2 & $54.7 \pm 2.6$ & 1.12 & 15 & 16 & 0.94 \\
\hline 36 & 3.51 & 2663.46 & 1207.27 & 15242.68 & 6 & $57.4 \pm 1.7$ & 1.32 & 17 & 18 & 0.94 \\
\hline 37 & 2.20 & 1089.23 & 1172.90 & 16050.33 & 4 & $62.4 \pm 4.6$ & 1.19 & 9 & 9 & 1.00 \\
\hline
\end{tabular}

Isolation 1 is given as distance to the nearest larger park

Isolation 2 is given as distance to the largest unfragmented woodlot Laoshan (the regional species pool)

Distance represents the distance of the park to the city center

$S_{\text {obs }}$ observed species richness; $S_{\text {exp }}$ expected species richness; $S_{\text {com }}$ survey completeness

level. Noise level in each park was expressed as arithmetic mean \pm standard deviation (SD) (Table 1). The distance to city center was measured as the distance from park center to the Xinjiekou Jinling Hotel, the center of Nanjing, which could be used as an indicator of the degree of urbanization. To evaluate the influence of habitat diversity on bird species richness, we observed and recorded the habitat types in which birds occurred during the survey (Wang et al. 2013). Considering the requirements of birds, we divided all the habitats into the following 12 
types: (1) broad-leaved forest, (2) coniferous forest, (3) coniferous broad-leaved mixed forest, (4) dense shrub, (5) sparse shrub, (6) short trees, (7) medium high trees, (8) high trees, (9) water area, (10) clearing, (11) hill, and (12) building (Additional file 1: Table S1).

\section{Data analyses}

\section{Species sampling completeness}

The species accumulation curve is widely used to judge the sampling adequacy and estimate the true species richness (Colwell et al. 2004). We thus evaluated bird inventory completeness with species accumulation curve (Colwell et al. 2004; Xu et al. 2017). We used the common nonparametric estimator Chao 1 to estimate the expected true number of bird species $\left(S_{\text {exp }}\right)$ in each park (Chao et al. 2005). Specifically, Chao 1 first estimates the number of species missed during sampling using the number of singletons and doubletons observed, and then adds this number to the observed number of species $\left(S_{\text {obs }}\right)$ to obtain an estimated total number of species (Chao et al. 2005). We then used the expected true species richness of birds $\left(S_{\text {exp }}\right)$ for the following analyses (Table 1; Bogich et al. 2012). The sampling adequacy analyses were performed using the "vegan" package (Oksanen et al. 2019) in R 4.0.0 (R Core Team 2020).

\section{Impacts of park characteristics on bird species richness}

Before the analyses, we used the Shapiro-Wilk test to determine whether the response variable $\left(S_{\text {exp }}\right)$ and the six predictor variables were normally distributed (Zar 2010). The results showed that $S_{\text {exp }}$, park area, distance to city center, shape index and habitat diversity did not follow the normal distribution $(p<0.05)$. Therefore, these variables were $\log _{10}$ transformed to normalize values.

We performed the following analyses in four steps to determine the influences of park characteristics on bird species richness. As variables with strong correlation $(|r|>0.7)$ would lead to similar ecological phenomena (Dormann et al. 2013), we first used Pearson correlation tests to check the pairwise correlations between the six predictor variables. As the correlation coefficients of the six variables were all smaller than 0.7 (Additional file 1: Table S2), we retained all of them in the following analyses. Second, we built a set of candidate models by combining the variables retained in the first step. We used the corrected Akaike information criterion $\left(\mathrm{AIC}_{\mathrm{c}}\right)$ to select and rank models. The models with $\Delta \mathrm{AIC}_{\mathrm{c}}<2$ were considered to have substantial support (Burnham and Anderson 2002). Furthermore, we obtained the Akaike weight $\left(w_{\mathrm{i}}\right)$ of each model by calculating the difference between $\mathrm{AIC}_{\mathrm{c}}$ value $\left(\triangle \mathrm{AIC} \mathrm{C}_{\mathrm{c}}\right)$. The Akaike weight $\left(w_{\mathrm{i}}\right)$ is the probability that the model is the best in all candidate models (Burnham and Anderson 2002). Finally, since
Akaike weight $\left(w_{\mathrm{i}}\right)$ indicated that no model was obviously the best $\left(w_{\mathrm{i}}>0.9\right)$ (Additional file 1: Table S3) (Anderson et al. 2001), we used the model average method to calculate the relative importance $\left(w_{+}\right)$, averaged parameter estimates and unconditional standard errors (SE) for models in the 95\% confidence set. The "MuMIn" package (Bartoń 2020) was used to carry out model average. All statistical analysis was performed in R 4.0.0 (R Core Team 2020).

\section{Results}

\section{General survey results}

We observed a total of 76 bird species during the survey period in the 37 study parks. The observed bird species richness in each park varied from 9 to 44 (Table 1 ). According to the expected true species richness $\left(S_{\text {exp }}\right)$, the average survey completeness for the 37 parks was $88 \%$, ranging from 73 to $100 \%$ (Table 1 ). Meanwhile, the species accumulation curve approached an asymptote (Fig. 2), indicating a high level of bird inventory completeness for the 37 study parks.

\section{Impacts of park characteristics on bird species richness}

Based on the model selection criterion of $\mathrm{AIC}_{\mathrm{c}}$, the multivariable model incorporating park area, habitat diversity, distance to the nearest larger park (isolation1), and distance to city center was the best model that affected the expected true species richness of birds in Nanjing city parks $\left(\triangle \mathrm{AIC}_{\mathrm{c}}=0, R^{2}=0.8190\right)$ (Table 2 , Additional file 1: Table S3). However, the small Akaike weight $\left(w_{\mathrm{i}}\right)$ of 0.3720 of the best model suggested substantial model selection uncertainty.

The results of model average showed that park area $\left(w_{+}=1, p<0.001\right)$, habitat diversity $\left(w_{+}=1, p<0.001\right)$, and distance to city center $\left(w_{+}=1, p<0.001\right)$ were the

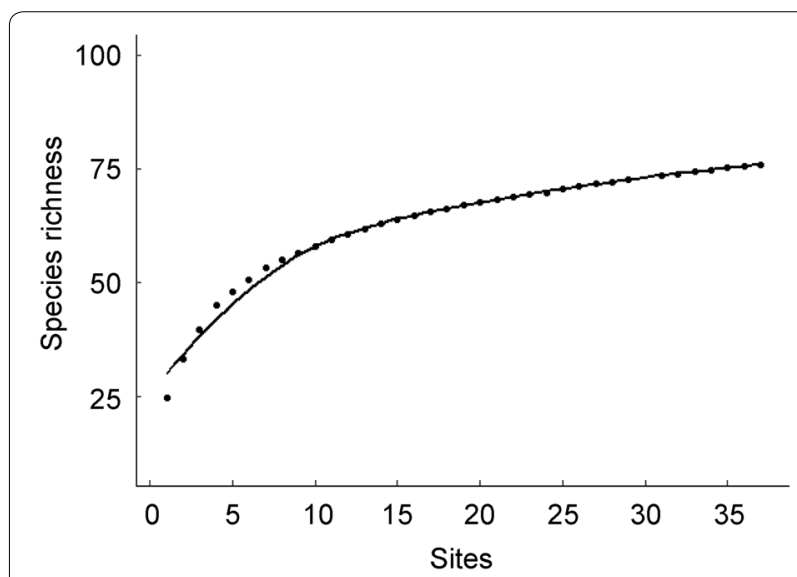

Fig. 2 Species-accumulation curve for birds in the 37 urban parks of Nanjing, China 
Table 2 Results of model selection relating bird species richness to predictor variables using corrected Akaike information criterion $\left(\mathrm{AIC}_{\mathrm{c}}\right.$ )

\begin{tabular}{|c|c|c|c|c|c|}
\hline Model & $K$ & $\mathrm{AIC}_{\mathrm{c}}$ & $\Delta \mathrm{AIC}_{\mathrm{c}}$ & $w_{\mathrm{i}}$ & Adjusted $R^{2}$ \\
\hline Area + Distance + HD + Isolation1 & 6 & -78.60 & 0 & 0.3720 & 0.8190 \\
\hline Area + Noise + Distance + HD + Isolation 1 & 7 & -77.48 & 1.12 & 0.2125 & 0.8227 \\
\hline Area $+\mathrm{SI}+$ Distance $+\mathrm{HD}+$ Isolation 1 & 7 & -75.87 & 2.73 & 0.0950 & 0.8148 \\
\hline Area + Distance + HD + Isolation2 + Isolation1 & 7 & -75.54 & 3.06 & 0.0805 & 0.8131 \\
\hline Area + Noise $+\mathrm{SI}+$ Distance $+\mathrm{HD}+$ Isolation 1 & 8 & -74.54 & 4.06 & 0.0489 & 0.8185 \\
\hline Area + Noise + Distance + HD + Isolation2 + Isolation 1 & 8 & -74.22 & 4.38 & 0.0416 & 0.8169 \\
\hline Area + Noise + Distance + HD & 6 & -74.15 & 4.45 & 0.0402 & 0.7959 \\
\hline Area + Distance +HD & 5 & -73.83 & 4.77 & 0.0343 & 0.7842 \\
\hline Area $+\mathrm{SI}+$ Distance $+\mathrm{HD}+$ Isolation2 + Isolation1 & 8 & -72.59 & 6.01 & 0.0184 & 0.8087 \\
\hline Area + Noise + SI + Distance + HD & 7 & -71.46 & 7.14 & 0.0105 & 0.7914 \\
\hline Area $+\mathrm{SI}+$ Distance $+\mathrm{HD}$ & 6 & -71.32 & 7.28 & 0.0098 & 0.7796 \\
\hline Area + Noise + Distance + HD + Isolation2 & 7 & -71.13 & 7.47 & 0.0089 & 0.7895 \\
\hline Area + Noise $+\mathrm{SI}+$ Distance $+\mathrm{HD}+$ Isolation2 + Isolation 1 & 9 & -71.03 & 7.57 & 0.0084 & 0.8122 \\
\hline Area + Distance $+\mathrm{HD}+$ Isolation2 & 6 & -70.97 & 7.63 & 0.0082 & 0.7775 \\
\hline
\end{tabular}

Models with $\Delta \mathrm{AIC}<10$, number of estimable parameters $(K)$, Akaike difference $(\Delta \mathrm{AIC})$, Akaike weight $\left(w_{\mathrm{i}}\right)$ and adjusted $R^{2}$ were listed. $\mathrm{SI}=\mathrm{Shape} \mathrm{Index} ; \mathrm{HD}=\mathrm{Habitat}$ Diversity. All candidate models were listed in Additional file 1: Table S3. See Table 1 for the abbreviated variables

most important predictors of the expected true species richness $\left(S_{\text {exp }}\right)$ of birds in Nanjing city parks (Table 3$)$. Moreover, they were all significantly and positively correlated with bird species richness (Fig. 3). By contrast, park shape $\left(w_{+}=0.20\right)$, environmental noise $\left(w_{+}=0.36\right)$, isolation $1\left(w_{+}=0.84\right)$ and isolation2 $\left(w_{+}=0.17\right)$ had little or no influences on bird diversity $(p>0.05$, Table 3$)$.

\section{Discussion}

In this study we investigated the influence of park characteristics on bird diversity in Nanjing city parks. We found that park area, habitat diversity and distance to city center were three most important factors positively affecting bird species richness in our system. So far, there is no study in Nanjing to explore the impact of urbanization on bird diversity. Our research thus filled in a significant gap and would have important implications for future urban planning and biodiversity conservation in our study system.

We found that park area was the most important predictor of bird species richness, verifying our initial hypothesis. Larger parks have more bird species than smaller ones, which is consistent with the prediction of species-area theory (MacArthur and Wilson 1967; Murgui 2007). The result is also in accord with some previous fragmentation studies in urbanized landscapes (Oliver et al. 2011; Zhou and Chu 2012). Larger parks can provide larger ecological space, more habitat types and food resources for birds, which is conducive for the establishment of a rich and stable population of birds (Evans et al. 2009; Liu et al. 2019). Meanwhile, large parks can accommodate certain rare species that are not common in small parks (e.g.

Table 3 Model-averaged parameter estimates, unconditional standard errors (SE) and relative variable importance ( $\left.w_{+}\right)$ for each variable in the $\mathbf{9 5 \%}$ confidence set

\begin{tabular}{|c|c|c|c|c|c|}
\hline Variables & $w_{+}$ & Estimate & Unconditional SE & $Z$ value & $p$ \\
\hline Intercept & / & 0.4710 & 0.3334 & 1.379 & 0.1679 \\
\hline Area & 1.00 & 0.1479 & 0.0322 & 4.417 & $1.00 \times 10^{-5}$ \\
\hline Habitat diversity & 1.00 & 0.5164 & 0.0926 & 5.362 & $1.00 \times 10^{-7}$ \\
\hline Distance & 1.00 & 0.1790 & 0.0462 & 3.731 & 0.0002 \\
\hline Isolation 1 & 0.84 & -0.0492 & 0.0025 & 1.949 & 0.0910 \\
\hline Noise & 0.36 & -0.0024 & 0.0044 & 0.539 & 0.5902 \\
\hline Shape index & 0.20 & 0.0141 & 0.0718 & 0.190 & 0.8490 \\
\hline Isolation2 & 0.17 & $-6.85 \times 10^{-9}$ & $1.18 \times 10^{-6}$ & 0.006 & 0.9955 \\
\hline
\end{tabular}

See Table 1 for the abbreviated variables 

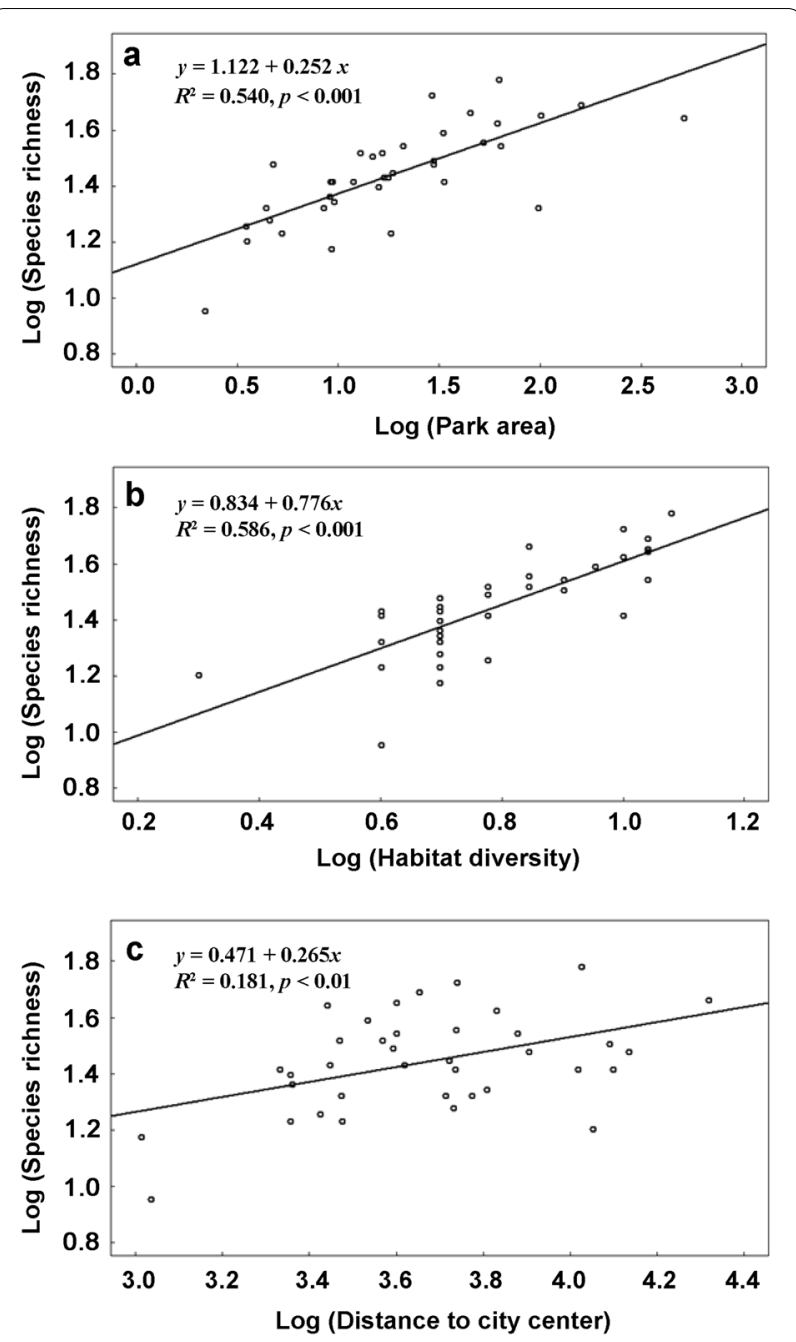

Fig. 3 Effects of park area (a), habitat diversity (b) and distance to city center (c) on bird species richness in the 37 urban parks of Nanjing, China

Gracupica nigricollis, Myophonus caeruleus, Pycnonotus jocosus). These uncommon species that only appear in large parks increase the species diversity of urban birds in our system.

Our results support our hypothesis that habitat diversity would positively affect bird species richness in urban parks. Abundant habitat types can meet the requirements of different living space of birds so as to improve the bird diversity in cities. We also found that the attraction of different types of habitats to birds was different. Broad-leaved forests, coniferous broad-leaved mixed forests, high trees, medium high trees and dense shrubs had a high level of bird species, while bird diversity in coniferous forest, grassland and buildings was quite low. Broad-leaved forests, medium high trees and dense shrubs could provide more hidden refuges and food sources for birds (Imai and Nakashizuka 2010; Rousseau et al. 2015). In addition, there are 15 species of water birds in our study, accounting for nearly $20 \%$ of the total species (76 species). The existence of water area (ponds, lakes, streams or rivers) in the parks contributes to the increase of bird diversity because larger water areas can provide more opportunities for birds to forage and nest, especially for those species associated with water (Chamberlain et al. 2010). In our surveys, we found that some water birds (e.g. Dendrocopos canicapillus, Gallinula chloropus, Amaurornis akool) only existed in the parks with ponds and lakes. Previous study has shown that smaller urban parks can also have higher bird diversity if water bodies and diverse vegetation are properly managed (Kim et al. 2007).

Our results are also consistent with the prediction that the distance to city center has positive effects on bird species richness. The distance to city center is often used as an indicator of the degree of urbanization, with shorter distance indicating higher urbanization (Chen et al. 2000; Wang et al. 2004). Our results suggest that the shorter distance is the park from city center, the lower is the bird diversity. As the distance from city center increases, the degree of urbanization and human interference decreases and the proportion of natural forests increases (Chen et al. 2000; Wang et al. 2004), which in turn will result in the increase of bird diversity in the remote parks.

Park shape could play an important role in urban biodiversity and ecological function (Martínez-Morales 2005; Ewers and Didham 2007). However, contrary to our expectation, the shape of the parks was not significantly correlated with bird species richness in our study. Different fragment shapes have more or less internal habitats, such as circular patches tend to have more internal habitats and less edge habitats, while linear ones would have more edges than internal habitats (Beck 2013). There is a certain quantitative relationship among total patch area, core area and edge area in fragments. In general, when the patch area increases, the core area increases faster than the edge area. When the patch area decreases, however, the difference between the core area and the edgeaffected habitat becomes smaller or no longer exists, and the whole patch is often occupied by marginal species or insensitive species (Laurance and Yensen 1991). Therefore, compared with large parks, the edge effect in small parks is much stronger. In our study, there were few linear and elongated parks (Fig. 1), and most of the parks had relatively larger area ( $>10 \mathrm{ha})$, which could support more internal species. Therefore, the shape index of parks had no significant impact on bird diversity in our system.

There was no significant correlation between park isolation and bird species richness in Nanjing city parks. In 
other words, the distance between the regional species pools and the urban park had no effect on the bird richness in our study. At least three reasons may explain why the correlations are weak. First, the isolation distance between the park and the species pool was relatively small (Fig. 1). Second, birds often have strong dispersal ability and could spread and communicate easily among different urban parks (Wang et al. 2013). Finally, wooded streets in Nanjing city can reduce the degree of regional isolation by increasing connectivity between parks (Fernández-Juricic and Jokimäki 2001).

Bird diversity and distribution may be affected by human activities and environmental noise (such as traffic noise and construction noise) in urban green space (Campbell 2009; Wang et al. 2013). Generally, environmental noise has a negative impact on bird diversity (Herrera-Montes and Aide 2011; Zhou and Chu 2012). However, our previous prediction that environmental noise would negatively affect bird species richness was not verified. The noise level had no significant effects on bird species richness probably because most birds recorded in our surveys were common urban birds. Such species always inhabited urban parks, and some birds could be found in almost all the parks, such as Cyanopica cyanus, Passer montanus, Streptopelias, Pycnonotus sinensis, Turdus mandarinus, which may have already adapted to the highly urbanized environment (Wang et al. 2008, 2009, 2015; Jasmani et al. 2016).

\section{Conclusions}

In the context of global and accelerating urbanization, the study of bird diversity and the underlying process has important implications for conservation and can be used to direct management efforts in urban ecosystems (Wang et al. 2013). Our study highlights the importance of park area, habitat diversity and the distance to city center in determining bird diversity in Nanjing city parks. These findings have several important implications for the urban park planning and bird diversity conservation in our system. First, large parks in urban areas should be maintained or enlarged because these parks will provide larger niche space, greater habitat diversity and resource availability for birds (Stein et al. 2014; Schütz and Schulze 2015). In addition, our study highlights the positive impact of habitat diversity on bird species richness. Therefore, to maximize the number of species in our system, conservation efforts should focus on increasing the habitat diversity and vegetation structure complexity of existing parks. Finally, remote parks far away from city center in our system should also be conserved because the distance of parks to city center has positive effects on bird diversity. To sum up, large parks with complex and diverse habitats far away from city center should be retained or constructed to increase bird diversity in urban design and planning in our system.

\section{Supplementary information}

Supplementary information accompanies this paper at https://doi. org/10.1186/s40657-020-00234-5.

Additional file 1: Table S1. Descriptions of habitat structural feature. Table S2. Pearson correlation matrix for predictor variables in 37 urban parks in Nanjing, China. Table S3. Results of model selection relating bird species richness to predictor variables using corrected Akaike information criterion (AICC).

\section{Authors' contributions}

YW conceived the study. XY and XT collected the data. XY and CC performed the analyses. $X Y$ wrote the first draft of the paper. $Y W$ revised the manuscript sustainably. All authors read and approved the final manuscript.

\section{Funding}

This work was supported by the National Natural Science Foundation of China (Grant No. 31971545 and 31770462) and Natural Science Foundation of Zhejiang Province (LZ18C030002).

\section{Availability of data and materials}

All data generated or analyzed during this study are included in this published article (and its Additional file 1).

\section{Ethics approval and consent to participate}

Not applicable.

\section{Consent for publication}

Not applicable.

\section{Competing interests}

The authors declare that they have no competing interests. The funders have no role in study design, data collection and analysis, decision to publish, or preparation of the manuscript.

Received: 5 August 2020 Accepted: 5 November 2020

Published online: 18 November 2020

\section{References}

Aronson MFJ, La Sorte FA, Nilon CH, Katti M, Goddard MA, Lepczyk CA. A global analysis of the impacts of urbanization on bird and plant diversity reveals key anthropogenic drivers. Proc R Soc B-Biol Sci. 2014;281:20133330.

Anderson DR, Link WA, Johnson DH, Burnham KP. Suggestions for presenting the results of data anlyses. J Wildl Manage. 2001;65:373-8.

Bartoń K. MuMIn: Multi-model inference. R package version 1.43.17. 2020. https://CRAN.R-project.org/package=MuMIn. Accessed 30 May 2020.

Beck T. Principles of ecological landscape design. Washington DC: Island Press; 2013.

Bibby C, Burgess N, Hill D, Mustoe S. Bird census techniques (2nd edition). London: Academic Press; 2000.

Bogich TL, Barker GM, Mahlfeld K, Climo F, Green R, Balmford A. Fragmentation, grazing and the species-area relationship. Ecography. 2012;35:224-31.

Burnham KP, Anderson DR. Model selection and multimodel inference: a practical information-theoretic approach. New York: Springer; 2002.

Campbell MON. The impact of habitat characteristics on bird presence and the implications for wildlife management in the environs of Ottakwa Canada. Urban Urban Green. 2009;8:87-95.

Chamberlain DE, Gough S, Vaughan H, Vickery JA, Appleton GF. Determinants of bird species richness in public green spaces. Bird Study. 2010;54:87-97.

Chao A, Chazdon RL, Colwell RK, Shen TJ. A new statistical approach for assessing similarity of species composition with incidence and abundance data. Ecol Lett. 2005:8:148-59. 
Chen S, Ding P, Zheng G, Zhu G. Impacts of urbanization on the wetland waterbird communities in Hangzhou. Zool Res. 2000;21:279-85 (In Chinese).

Chen S, Wang S. Bird diversities and their responses to urbanization in China. In: Murgui E, Hedblom M, editors. Ecology and conservation of birds in urban environments. Switzerland: Springer; 2017. p. 55-74.

Colwell RK, Mao CX, Chang J. Interpolating, extrapolating, and comparing incidence-based species accumulation curves. Ecology. 2004;85:2717-27.

$\mathrm{Cui} \mathrm{H}$. The investigation and research on plant community of heritage parks in Nanjing. Master Thesis. Nanjing: Nanjing Agricultural University. 2015 (In Chinese).

Ding $\mathrm{H}$, Shi $\mathrm{H}$. The surface temperature and land use change analysis of Nanjing based on time series data. The 34th Annual Meeting of China Meteorological Society, Zhengzhou. 2017; 233-47 (In Chinese).

Dormann CF, Elith J, Bacher S, Buchmann C, Carl G, Carré G, et al. Collinearity: a review of methods to deal with it and a simulation study evaluating their performance. Ecography. 2013;36:27-46.

Evans KL, Newson SE, Gaston KJ. Habitat influences on urban avian assemblages. Ibis. 2009;151:19-39.

Ewers RM, Didham RK. The effect of fragment shape and species' sensitivity to habitat edges on animal population size. Conserv Biol. 2007;21:926-36.

Ferenc M, Sedláček O, Fuchs R, Dinetti M, Fraissinet M, Storch D. Are cities different? Patterns of species richness and beta diversity of urban bird communities and regional species assemblages in Europe. Global Ecol Biogeogr. 2014;23:479-89.

Fernández-Juricic E. Bird community composition patterns in urban parks of Madrid: the role of age, size and isolation. Ecol Res. 2000;15:373-83.

Fernández-Juricic E, Jokimäki J. A habitat island approach to conserving birds in urban landscapes-case studies from southern and northern Europe. Biodivers Conserv. 2001;10:2023-43.

Gagné SA, Sherman PJ, Singh KK, Meentemeyer RK. The effect of human population size on the breeding bird diversity of urban regions. Biodivers Conserv. 2016;25:653-71.

Grimm NB, Faeth SH, Golubiewski NE, Redman CL, Wu J, Bai X, et al. Global change and the ecology of cities. Science. 2008;319:756-60.

Herrera-Montes MI, Aide TM. Impacts of traffic noise on anuran and bird communities. Urban Ecosyst. 2011;14:415-27.

Hagen EO, Hagen O, Ibanez-Alamo JD, Petchey OL, Evans KL. Impacts of urban areas and their characteristics on avian functional diversity. Front Ecol Evol. 2017:5:84.

Imai H, Nakashizuka T. Environmental factors affecting the composition and diversity of avian community in mid-to late breeding season in urban parks and green spaces. Landsc Urban Plan. 2010;96:183-94.

Jasmani Z, Ravn HP, van den Bosch CCK. The influence of small urban parks characteristics on bird diversity: a case study of Petaling Jaya Malaysia. Urban Ecosyst. 2016;20:227-43.

Kim J, Chae J, Koo T-H. Variation in bird diversity in relation to habitat size in the urban landscape of Seoul South Korea. Acta Ornithol. 2007:42:39-44.

Laurance WF, Yensen E. Predicting the impacts of edge effects in fragmented habitats. Biol Conserv. 1991;55:77-92.

Lepczyk CA, Warren PS. Urban bird ecology and conservation. Berkeley: University of California Press; 2012.

Liu J, Bai H, Ma H, Feng G. Bird diversity in Chinese urban parks was more associated with natural factors than anthropogenic factors. Urban For Urban Green. 2019:43:126358.

MacArthur RH, Wilson EO. The theory of island biogeography. Princeton: Princeton University Press; 1967.

Mackinnon J, Phillipps K. A field guide to the birds of China. Oxford: Oxford University Press; 2000

Martinez-Morales MA. Landscape patterns influencing bird assemblages in a fragmented neotropical cloud forest. Biol Conserv. 2005; 121: 117-26.

Morelli F, Benedetti Y, Su T, Zhou B, Moravec D, Símová P, et al. Taxonomic diversity, functional diversity and evolutionary uniqueness in bird communities of Beijing's urban parks: effects of land use and vegetation structure. Urban Urban Green. 2017;23:84-92.

Murgui E. Effects of seasonality on the species-area relationship: a case study with birds in urban parks. Glob Ecol Biogeogr. 2007;16:319-29.

Nemeth E, Brumm H. Birds and anthropogenic noise: are urban songs adaptive? Am Nat. 2010;176:465-75.

Oksanen J, Blanchet FG, Friendly M, Kindt R, Legendre P, McGlinn D, et al. vegan: Community Ecology Package. R package version 2.5-6. 2019. https://CRAN.R-project.org/package=vegan. Accessed 16 Jul. 2020.

Oliver AJ, Hong-Wa C, Devonshire J, Olea KR, Rivas GF, Gahl MK. Avifauna richness enhanced in large, isolated urban parks. Landsc Urban Plan. 2011;102:215-25.

R Core Team. R: A language and environment for statistical computing. R Foundation for Statistical Computing, Vienna, Austria. 2020. https:// www.R-project.org/. Accessed 11 May 2020.

Ricklefs RE, Lovette IJ. The roles of island area per se and habitat diversity in the species-area relationships of four Lesser Antillean faunal groups. J Anim Ecol. 1999;68:1142-60.

Rousseau JS, Savard J-PL, Titman R. Shrub-nesting birds in urban habitats: their abundance and association with vegetation. Urban Ecosyst. 2015;18:871-84.

Schütz C, Schulze CH. Functional diversity of urban bird communities: effects of landscape composition, green space area and vegetation cover. Ecol Evol. 2015:5:5230-9.

Stein A, Gerstner K, Kreft H, Arita H. Environmental heterogeneity as a universal driver of species richness across taxa, biomes and spatial scales. Ecol Lett. 2014;17:866-80.

Tan X, Yang X, Chen C, Wang Y. Nestedness and underlying processes of bird assemblages in Nanjing city parks. Curr Zool. 2020. https://doi. org/10.1093/cz/zoaa069.

Tong L. Studies on community structure and the optimized models of urban forest in Nanjing. PhD Thesis. Nanjing: Nanjing Forestry University. 2007 (In Chinese)

Wang Y, Chen S, Ping D. Effects of urbanization on the winter bird foraging guilds. J Zhejiang Univ (Sci Ed). 2004;31:330-6 (In Chinese).

Wang Y, Chen S, Jiang P, Ding P. Black-billed Magpies (Pica pica) adjust nest characteristics to adapt to urbanization in Hangzhou. China Can J Zool. 2008;86:676-84.

Wang Y, Chen S, Blair RB, Jiang P, Ding P. Nest composition adjustments by Chinese Bulbuls Pycnonotus sinensis in an urbanized landscape of Hangzhou (E China). Acta Ornithol. 2009;44:185-92.

Wang Y, Bao Y, Yu M, Xu G, Ding P. Nestedness for different reasons: the distributions of birds, lizards and small mammals on islands of an inundated lake. Divers Distrib. 2010;16:862-73.

Wang Y, Ding P, Chen S, Zheng G. Nestedness of bird assemblages on urban woodlots: implications for conservation. Landsc Urban Plan. 2013;111:59-67.

Wang Y, Huang Q, Lan S, Zhang Q, Chen S. Common blackbirds Turdus merula use anthropogenic structures as nesting sites in an urbanized landscape. Curr Zool. 2015;61:435-43.

Xu A, Han X, Zhang X, Millien V, Wang Y. Nestedness of butterfly assemblages in the Zhoushan Archipelago, China: area effects, life-history traits and conservation implications. Biodivers Conserv 2017:26:1375-92.

Zar JH. Biostatistical analysis (Fifth edition). New Jersey: Prentice-Hall; 2010.

Zheng G. A checklist on the classification and distribution of the birds of China (Third edition). Beijing: Science Press; 2017. (In Chinese).

Zhou D, Chu LM. How would size, age, human disturbance, and vegetation structure affect bird communities of urban parks in different seasons? J Ornithol. 2012;153:1101-12 